\title{
Correction to: Experiences of early graduate medical students working in New York hospitals during the COVID-19 pandemic: a mixed methods study
}

Harrison D. Pravder ${ }^{1}$, Liana Langdon-Embry ${ }^{1}$, Rafael J. Hernandez ${ }^{1}$, Nicholas Berbari ${ }^{2}$, Steven P. Shelov ${ }^{2}$ and Wendy L. Kinzler ${ }^{2^{*}}$

Correction to: BMC Med Educ 21, 118 (2021) https://doi.org/10.1186/s12909-021-02543-9

Following publication of the original article [1], we have been informed that Figs. 1 and 2 were published in low quality and with duplicate figure legends.

The original article has been corrected.

\section{Author details}

'Renaissance School of Medicine, Stony Brook University, HSC T4-147, Stony Brook, NY 11794, USA. ${ }^{2}$ NYU Long Island School of Medicine, NYU Langone Hospital - Long Island, 222 Station Plaza, Fifth Floor, Suite 510, Mineola, NY 11501, USA.

Published online: 17 March 2021

\section{Reference}

1. Pravder, et al. Experiences of early graduate medical students working in

New York hospitals during the COVID-19 pandemic: a mixed methods study. BMC Med Educ. 2021;21:118 https://doi.org/10.1186/s12909-021-02 543-9.

The original article can be found online at https://doi.org/10.1186/s12909021-02543-9.

* Correspondence: wendy.kinzler@nyulangone.org

${ }^{2} \mathrm{NYU}$ Long Island School of Medicine, NYU Langone Hospital - Long Island,

222 Station Plaza, Fifth Floor, Suite 510, Mineola, NY 11501, USA

Full list of author information is available at the end of the article

(c) The Author(s). 2021 Open Access This article is licensed under a Creative Commons Attribution 4.0 International License, which permits use, sharing, adaptation, distribution and reproduction in any medium or format, as long as you give appropriate credit to the original author(s) and the source, provide a link to the Creative Commons licence, and indicate if changes were made. The images or other third party material in this article are included in the article's Creative Commons licence, unless indicated otherwise in a credit line to the material. If material is not included in the article's Creative Commons licence and your intended use is not permitted by statutory regulation or exceeds the permitted use, you will need to obtain permission directly from the copyright holder. To view a copy of this licence, visit http://creativecommons.org/licenses/by/4.0/ The Creative Commons Public Domain Dedication waiver (http://creativecommons.org/publicdomain/zero/1.0/) applies to the data made available in this article, unless otherwise stated in a credit line to the data. 


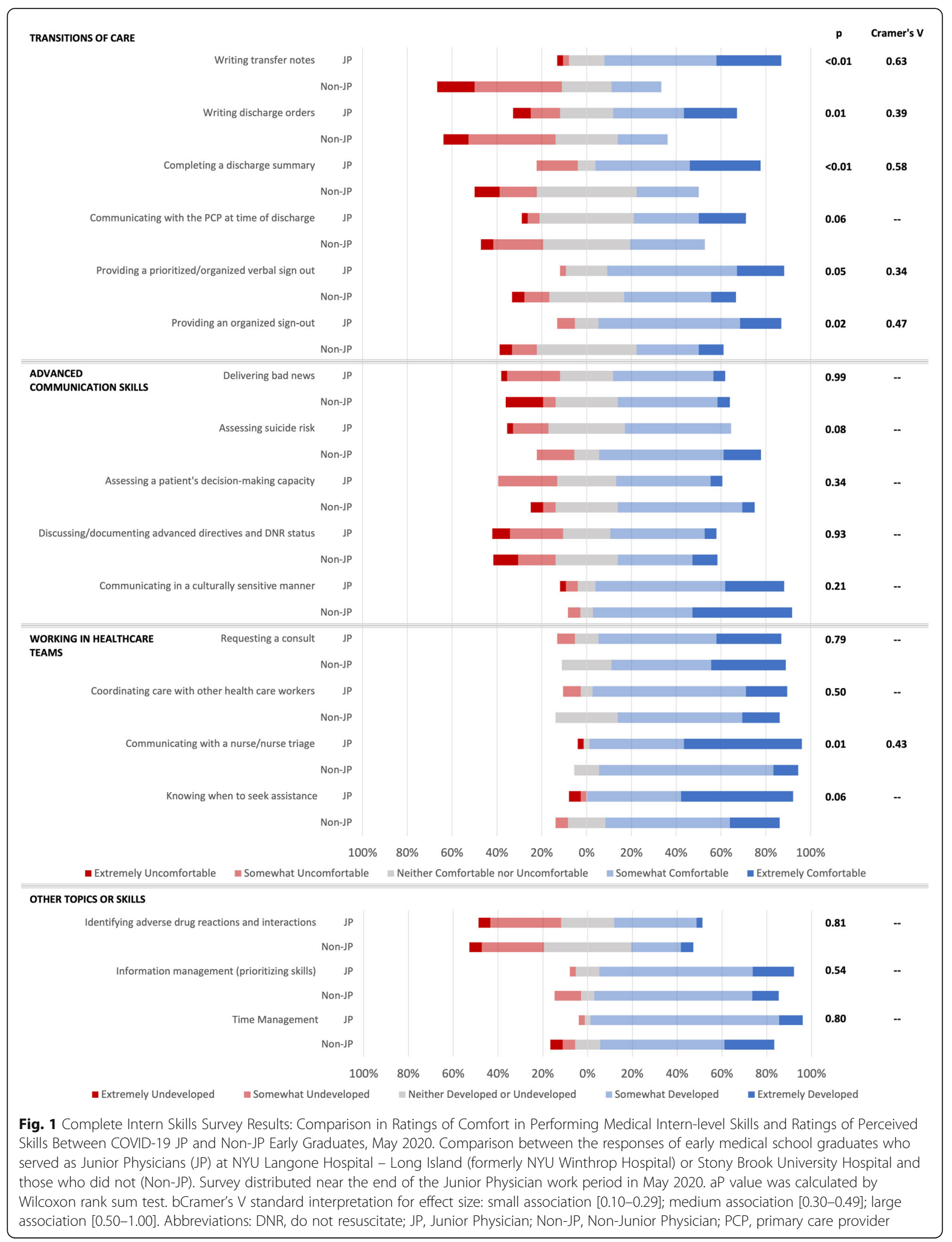




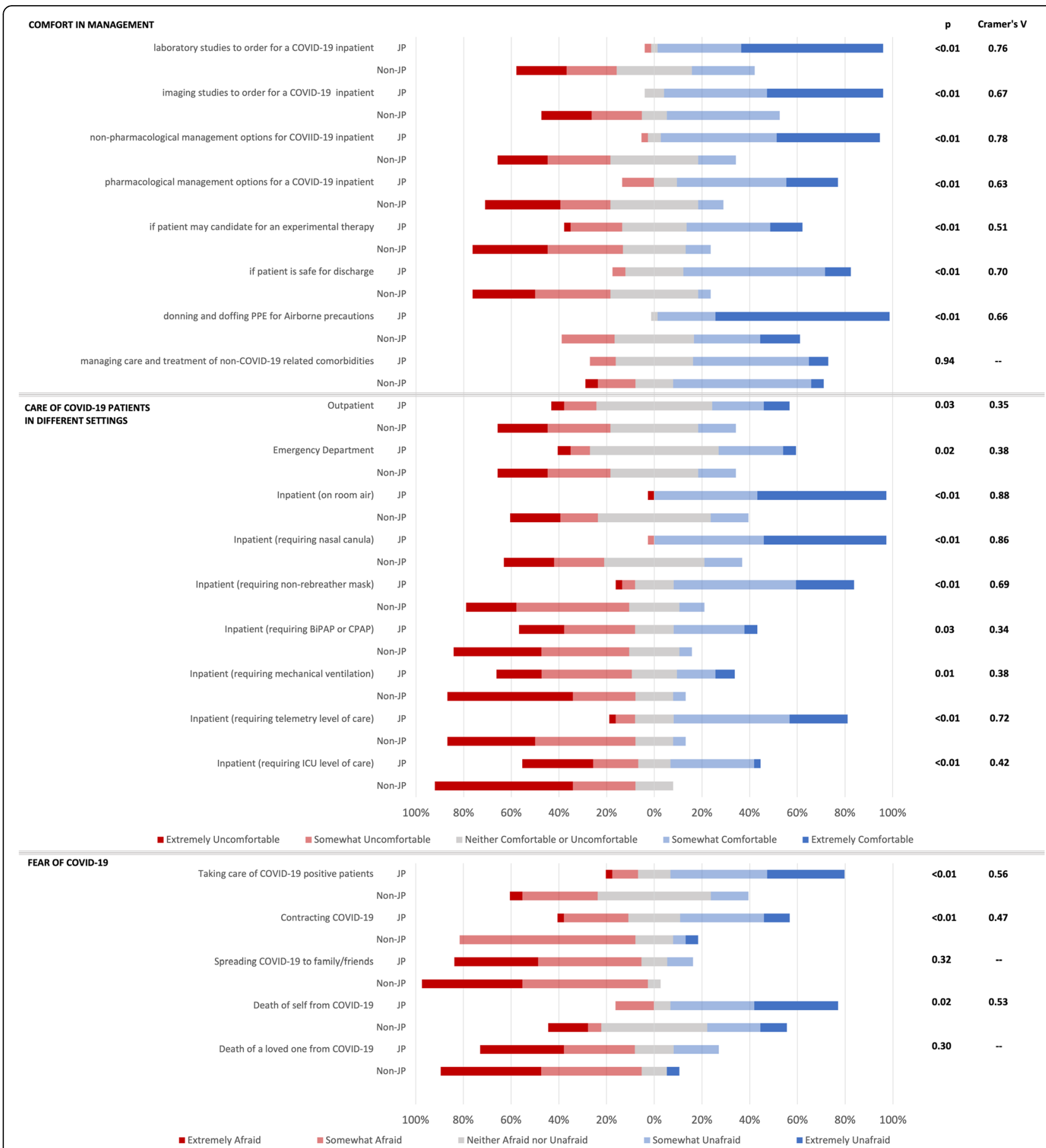

Fig. 2 COVID Care Survey Results: Comparison in Ratings of Comfort and Associated Fear in Managing COVID-19 Patients Between JP and Non-JP Early Graduates, May 2020. Comparison between the responses of early medical school graduates who served as Junior Physicians (JP) at NYU Langone Hospital - Long Island (formerly NYU Winthrop Hospital) or Stony Brook University Hospital and those who did not (Non-JP) during the COVID-19 pandemic. Survey distributed near the end of the Junior Physician work period in May 2020. aP value was calculated by Wilcoxon rank sum test. bCramer's $\vee$ standard interpretation for effect size: small association [0.10-0.29]; medium association [0.30-0.49]; large association [0.501.00]. Abbreviations: BiPAP, bilevel positive airway pressure; CPAP, continuous positive airway pressure; COVID-19, Coronavirus disease 2019; ICU, intensive care unit; JP, Junior Physician; Non-JP, Non-Junior Physician; PPE, personal protective equipment 